Las been of practical benefit. In former times it was quite exceptional to find the results of cancer surgery so fully reported that we can show them to have been disappointing by exact statistical records; yet no one doubts that they were bad, and the increasing severity of modern operations is based upon our conviction of the worthlessness of the earlier surgical procedure. In the present day there is much greater operative activity; yet there is the same lack of statistics. Quite recently Mr. Arbuthnot Lane ${ }^{1}$ of Guy's Hospital published "A Case illustrating a very Effectual Method of treating Extensive Malignant Disease of the Breast" from a single woman aged twenty-nine, who bad developed carcinoma of the right breast only five months previously. He remored the middle third of the clavicle, tied the subclavian artery and vein, and made a clean sweep of the subclavian triangle, though its glands were not obviously affected. Then he made an incision nine inches in length along the middle line of the sternum and extended the incision at what seemed a safe distance from the growth to the posterior fold of the axilla, and thence to the outer end of the clavicle. In order to cover this enormous wound, more than nine inches in diameter, he made a large and sufficient flap from the skin over the deltoid. Next, he amputated the arm at the shoulderjoint, and, lastly, he dissected all the soft parts from the sternum, clavicle, ribs, cartilages, intercostal muscles, serratus magnus, and posterior wall of the axilla. No one has commented upon an operation of such novel magnitude except Mr. Rutherford Morison of Newcastle-onTyne, who, it appears, ${ }^{2}$ had forestalled Mr. Lane upon two occasions. It is the logical outcome of our increased knowledge of the lymphatic anatomy of the breast, and now that a lead has been given it is likely to be followed more or less extensively. Comment, therefore, is almost obligatory. In Mr. Lane's patient the new growth was found to involve the greater pectoral muscle-a common occurrence, and one which absolutely prevents assurance of complete eradication of the disease, for it is impossible to remove the mediastinal glands which drain the pectoral muscles. It might be argued that as the mediastinal glands had to be left the glands of the neck, which were not obviously diseased, might as well have been left also; but the practical answer is that one must do what one can. There are, however, no statistics to show the results of the recent surgical treatment of cancer of the breast. The operations have increased in severity, but there is a suspicion that the results in prolongation of life are no better. It would, perhaps, be invidious to refer particularly to the many papers upon cancer surgery which have appeared during the past decade. Availing myself of the meagre statistics to hand, I endeavoured to show, in a paper which I lately read before the Liverpool Medical Institution, that we possess no evidence such as would convince men of ordinary business capacity that life is prolonged by the numerous and heroic operations which are now performed upon patients with cancer of the breast, uterus, or alimentary canal. Events clearly show that malignant disease is constitutional, yet we act as if it had been conclusively proved to be a mere local affection. Sir James Paget has said that cancer of the breast does not fail to return after amputation more than once in 500 cases. Of course, as Mr. Bryant has recently pointed out, simple cysts of the breast are sometimes mistaken for cancer, and these, one need scarcely say, never return after removal. Chronic mastitis has also been mistaken for cancer. In rare and exceptional instances patients live for many years without securrence of their disease, which appeared to be cancerous, and ultimately die from something else. But it is freely admitted that in the large majority of cases death after operation for malignant disease is an affair of a few months. It is only by a serial and methodic investigation that these discrepant results can be explained. Such inquiry would be of the highest value to the profession, and I hope soon to take some part in promoting it. Even though the inquiry should prove unfavourable to the surgical measures which are now in vogue we shall not be content to sit helpless, with folded hands, for pathological research already gives promise of another and perhaps more scientific mode of treatment.

I am, Sirs, yours respectfully,

$$
\text { E. T. DAVIES, }
$$

Assistant Surgeon to the Hospital for Women, Iiverpool Jan. 5th, 1896

2 The Laxcet, Oet. 12th, 1895.
2 The LaNCeT, Oct. 19th, 1895.

\section{DIPHTHERIA AND ITS PROPAGATION BY MEANS OF SCHOOLS.}

To the Editors of THE LANCET.

SrRs,-There are many points in the reports of the various medical officers of health which are considered of trifling importance at the time and yet in the light of subsequent experience are proved to be of great value. The question in sanitary science which is occupying our minds most at the present time is as to the influences which are mostly at work in the production of diphtheria. One important observation has been made by Mr. Shirley Murphy, medical officer of health of the London County Council-viz., that an epidemic often breaks out when children meet together in the schools after the holidaysbut another, equally important, has been made by $\mathrm{Mr}$. Biddle-viz., that the cases fall off as the term goes on. And in order, if possible, to reconcile these apparently irreconcilable facts I have suggested that the cause of these school outbreaks may be due to imperfect flushing of drains during the holidays. In support of this contention I would cite a case which was told me by Dr. Gibbes, medical officer of health for the Kingston rural sanitary district, and no doubt put forward in one of his annual reports. Some time ago he said he had two or three outbreaks in the schools of a neighbouring village, and that, in spite of their being closed on more than one occasion, fresh outbreaks occurred immediately on their being reopened. At last he had the drain thoroughly well flushed with a strong solution of corrosive sublimate, and the epidemics then completely stopped. Of course this may have been a mere coincidence, but there could not possibly be any harm in having the drains thoroughly flushed with some strong antiseptic before each term commenced.

I am, Sirs, your obedient servant,

Surbiton, Jan. 6th, 1896

F. P. Atrinson.

\section{"ARE HOSPITALS TO BECOME MEDICAL CLUBS?" \\ To the Editors of THE LANCET}

SIRS,-In your issue of the 28th ult. (page 1671) you have an article on a meeting of the committee of the Swansea Hospital to discuss a report of the medical staff on this subject, in which you warn the working men not to be led by me save on military matters. However indifferent anyone may be to the smiles or frowns of public opinion, yet it is not pleasant to find your article repeated in the local papers. I see myself in the not very enviable position of being held up to the working men as one whose counsels are to be avoided, as if I had really been guilty of some crime in the opinion of others than THE LANCET but if you think you had cause to warn them against me I had, I consider, better and more just reason for warning them not to be led by a report in THE LANCET of a meeting of a hospital committee, more especially at Swansea, and I do protest against the unfair way you have placed the matter before the public." You state: "Colonel Morgan said in his opinion working men had a right to their admission, and the benefit need not necessarily be a charity. Where can right come in when, as everyone knows, the hospital was for serious cases which cannot be accommodated at home or paid for without straining a working man? As the chairman said, There are the rules-we cannot alter them." Now, who reading this would suppose that Colonel Morgan and the chairman were one and the same person? The only charitable conclusion I can arrive at is that you likewise did not realise it, and so unwittingly you made the same mistake as did Balaam the son of Beor some thousands of years ago. As regards the first part, from the way you put it it means one thing; but, had you not omitted to state that the only rights I claim for them are to select or nominate their cases the same as any other subscribers, it would then have meant something different. You ask, "Where can the right come?" I reply, because we have promised it, and we ought to keep our word. I enclose a letter I wrote to the Cambrian on this subject on Dec. 20th, in which you will see exactly what my ideas are, and if you will do me the honour to criticise them I am quite prepared to meet you as regards the conclusion arrived at by the hospital committee that "subscribers be requested to investigate the cases they recommend." I thought it answered all the requirements, and believe it is 